\title{
$O$ vídeo-digital em uma proposta de leitura em língua materna sob um enfoque discursivo
}

\author{
Luciana Cristina Dias Di Raimo \\ Universidade Estadual de Maringá \\ diaslucian@yahoo.com
}

\begin{abstract}
Resumo
Considerando o impacto das tecnologias digitais em práticas de leitura, apresentaremos uma abordagem discursiva de um vídeo disponibilizado no sítio eletrônico de Veja a respeito da cobertura da morte de Eduardo Campos. $\mathrm{Na}$ prática de leitura implementada, vale destacar que o vídeo nos permitiu problematizar alguns aspectos: (i) o efeito de evidência produzido pelo/no jornalismo eletrônico como modalidade na qual a informação é sintética e capaz de atingir sujeitos-leitores em larga escala; (ii) o processo de textualização do vídeo que se constitui não por um registro de uma série de ações, mas sim a partir da combinação de cenas congeladas do velório que organizam relações de contradições em torno do visível (cenas do velório) e do dito.
\end{abstract}

Palavras-chave: leitura discursiva. ensino de língua materna. vídeos digitais.

\begin{abstract}
Considering the impact of digital technologies on reading practices, we will present a discursive approach of a video available on the website of Veja about the coverage of the death of Eduardo Campos. Implemented in reading practice, it is noteworthy that the video allowed us to question some aspects: (i) the evidence of effect produced by / in electronic journalism as a form in which information is synthetic and capable of subject-readers on a large scale; (ii) the textualization process of the video that is not a record for a series of actions, but rather from the combination of frozen funeral scenes that organize contradictions of relationships around the visible (funeral scenes) and said.
\end{abstract}

Keywords: discursive reading. mother tongue teaching. digital-videos. 


\section{Gesto inicial}

O propósito deste artigo é apresentar uma proposta de leitura de cunho discursivo, voltada para acadêmicos do curso de Letras, na disciplina "Oficina de leitura e produção de textos", em uma universidade pública do Estado do Paraná, tendo-se em vista a imbricação verbal e visual na produção de sentidos de um vídeo digital sobre a morte de Eduardo Campos, em 2014, sob o título "Multidão se despede de Campos no Recife". Minha ancoragem teóricometodológica diz respeito à Análise do Discurso materialista, doravante $\mathrm{AD}$, que tem como base os estudos de Pêcheux e de Orlandi, além de reflexões sobre leitura discursiva advindas do campo da Linguística Aplicada (CORACINI, 1995, 2000; SERRANI, 2005, BOLOGNINI, 2009).

Acredito que o meio digital pode favorecer um trabalho no qual "toda palavra é sempre parte de um discurso" (ORLANDI, 2009), bem como encaminhar trajetos de leitura nos quais interessa ao professor e aos alunos compreender como materiais simbólicos diferentes (cor, imagem, som) produzem certos efeitos e não outros, com base em suas especificidades. Além disso, a leitura de vídeos digitais é atravessada pelo modo como o áudio, as imagens, as cores, os recursos de animação, com base na tecnologia digital, funcionam e produzem efeitos em leitores diversos.

Minha ancoragem na AD justifica-se pelo fato de que os vídeos não podem ser trabalhados como objetos neutros ou transparentes que informam uma dada mensagem ou escondem os sentidos. Ou ainda considerar o vídeo como um material cujo controle dos sentidos é total por parte do sujeito jornalista. Neste caso, interessa-me mobilizar os conceitos de "condições de produção", "formação discursiva" e "equívoco" na abordagem discursiva do vídeo digital de modo que a autoria - a possibilidade de o aluno produzir sentidos - se realize nas práticas propostas.

Uma vez que a $A D$ não trabalha com a premissa de que a linguagem não serve para comunicar no texto as intenções de um sujeito falante, entendemos que esse campo pode deslocar práticas de leitura nas quais o aluno é levado a somente captar ou desvendar os sentidos de um texto. Com efeito, o texto funciona como exemplar de um discurso maior e deve ser visto não como mero produto linguístico, 
mas sim como instância de um processo discursivo do qual fazem parte memórias discursivas e condições de produção. Nesse sentido, a AD me permite uma abordagem do texto que extrapole a dimensão do código e problematize o equívoco e a contradição na/da linguagem.

$\mathrm{O}$ artigo divide-se em três partes: na primeira, apresentarei reflexões teóricas que balizam uma proposta discursiva de leitura; na segunda, esboçarei uma análise pré-pedagógica do vídeo digital intitulado "Multidão se despede de Campos no Recife", disponibilizado no sítio eletrônico da Revista Veja, com o propósito de mobilizar conceitos tais como: condições de produção, formação discursiva e equívoco; e, na terceira parte, com base na análise empreendida, buscarei formular atividades e perguntas de leitura sobre o vídeo digital com base no jogo entre formulação e constituição dos sentidos, considerando uma turma do primeiro ano de Letras de uma universidade pública do Estado do Paraná.

\section{A perspectiva discursiva de leitura}

Antes de tudo, é preciso considerar que adotar ou privilegiar uma concepção de leitura nos coloca diante de uma encruzilhada, visto que a abordagem de um texto pode seguir diferentes percursos, tendose em mente o desenvolvimento da Linguística como ciência que estuda a linguagem humana ou mesmo a escolha de uma perspectiva ou abordagem do texto em sala de aula. Tendo em vista a proposta à qual estou filiada, neste caso, a discursiva, me interessa destacar que a leitura está sendo tomada não como mera atividade de recepção de um texto, mas como "efeito de sentidos entre locutores" (PẾCHEUX, 1990).

Coracini (2005), opondo-se a uma visão de sujeito uno, dono do seu dizer e com controle sobre a significação, tece críticas em relação a duas concepções clássicas de leitura que, na visão da autora, têm determinado nosso olhar sobre o objeto (texto, mundo, obra de arte, nós mesmos): (i) a leitura como decodificação - descoberta de um sentido (presente sobretudo na escola) e (ii) leitura como interação construção de um sentido - (presente sobretudo na academia). Apoiada nos pressupostos da análise do discurso de linha francesa e na teoria da 
desconstrução, as reflexões de Coracini, neste caso ligadas ao campo de estudos aplicados, repousam tanto em relação à abordagem estruturalista calcada na língua como código e na leitura como decodificação quanto em relação à visão interacionista, que, ao conceder ao leitor o papel de sujeito ativo na produção de sentido, também sustenta uma visão de que o sentido do texto é algo previsto e controlado, à espera da competência do leitor para sua (re)constituição.

Serrani (2005), outra estudiosa ligada aos estudos aplicados, também apresenta reflexões interessantes que nos levam a pensar na dimensão da leitura, considerando a articulação de princípios teóricometodológicos da análise de discurso ao preparo de aulas de línguas materna e estrangeira. Neste caso, as preocupações da autora decorrem do "questionamento de materiais didáticos e propostas, nas quais predomine uma apresentação de conteúdos e exercícios baseados exclusivamente na lógica da sentença e na dimensão informacional da linguagem" (SERRANI, 2005, p. 63).

Ademais, as reflexões de Bolognini (2007, p. 17) problematizam a transparência da linguagem e me levam a considerar que "os efeitos de sentido de um discurso estão presentes na linguagem, e não fora dela (entrelinhas, subliminarmente"), ou seja, os sentidos não estão colados às palavras, mas precisam ser vistos com base na relação texto/memória, isto é, a outros discursos anteriores que tornem um dizer possível e passível de fazer sentido.

Com efeito, pensar a leitura, de um ponto de vista discursivo, é levar às consequências, na prática de atribuição de sentidos, uma noção de sujeito como social e ideologicamente constituído. Neste caso, vale citar Pêcheux (1997), para o qual há duas formas de esquecimento ou ilusões discursivas que constituem o sujeito: o número 01 , da ordem da constituição, no qual temos a ilusão de que somos a origem e a fonte do que dizemos, quando retomamos sentidos preexistentes, e o esquecimento número 02 , da ordem da formulação, que nos dá a impressão de que aquilo que foi dito só poderia ter sido dito daquela forma, produzindo uma ilusão de realidade de pensamento, como se houvesse uma relação termo a termo entre linguagem/mundo. Trabalhar com essas ilusões discursivas e tirar proveito delas são possibilidades que a perspectiva de leitura discursiva me oferece.

De fato, à luz da $\mathrm{AD}$, especificamente uma proposta de leitura de um vídeo digital não pode ser entendida como atividade de 
apreensão de um sentido único preso à literalidade ou um processo de decodificação (descoberta do sentido) ou como um processo no qual ler se restringe a uma série de estratégias (ler as informações gerais e partir para as específicas), buscando apreender o que o texto quis dizer. É preciso entender que a linguagem serve para comunicar e para não comunicar (ORLANDI, 1999, p. 21). Ou ainda, que a língua não é um mero instrumento a ser controlado ou utilizado para informar conteúdo, a língua é um acontecimento no sujeito.

A leitura na era digital, pensada discursivamente, coloca em cena um novo olhar para a linguagem, o que pode contribuir para que a escola também repense seu lugar social: a própria natureza material do ciberespaço no tocante às novas tecnologias, linguagens e gêneros que perpassam tais práticas de leitura e a necessidade de conceber a imagem tomada também em sua opacidade (NECKEL, 2010). Do ponto de vista de uma análise materialista, é levar às consequências, nos termos de Lagazzi (2011, p. 2), "a produção do sentido acontecendo sobre uma base material sempre em condições que determinam essa produção".

Em se tratando do meio digital, é relevante pensar em que medida as condições de produção nas quais o avanço tecnológico emerge, bem como a compressão tempo/espaço trazida pelo advento da informatização, afetam, sobremaneira, os sujeitos inseridos nesse contexto e suas práticas de leitura atravessadas por todos os dizeres sobre o que é ler na era digital. Considerando as reflexões de Coracini (2002; 2005), é válido problematizar a noção de sujeito, dando visibilidade à sua heterogeneidade, fragmentação e fluidez.

Segundo Lagazzi (2011, p. 499), "no caso de um texto alocado no espaço digital, importam também os links, muitas vezes o movimento de imagens, a sonoridade e a musicalidade, em caso de vídeos". Dessa forma, a materialidade específica de vídeos digitais, em práticas de leitura em sala de aula de língua materna, consequentemente, leva-me a pensar na imbricação texto verbal, sonoro e imagético (envolvendo diferentes formas materiais significantes: grafia, desenho, fotografia, cor) e na produção de movimentos, animação, no que diz respeito à produção dos sentidos.

Tendo em vista o advento da internet, é preciso repensar o processo de constituição do sujeito leitor no ciberespaço, visto que há novas políticas de escrita/leitura se produzindo na web e afetando a 
relação desse sujeito com essas práticas. Não se lê nem se escreve mais como se lia e se escrevia em outras épocas. Nas palavras de Nunes (2010, p. 110):

\begin{abstract}
Enquanto a versão impressa é formulada para ser visualizada no conjunto, quer dizer, as informações são apresentadas de uma só vez no mesmo espaço significante pelo imbricamento verbo-visual, a versão eletrônica incorpora, além do imbricamento verbal-visual, outros elementos significantes como o som e o vídeo, elementos que não têm a possibilidade de circular na versão impressa, mas somente na eletrônica.
\end{abstract}

Segundo Dias e Couto (2011, p. 634), "se pensarmos, então, no discurso das novas tecnologias digitais, veremos que ele se constitui pela filiação aos sentidos de inovação, avanço tecnológico, novo, inclusão, internet, redes sociais e outros". Com efeito, o vídeo digital como forma de recorte de um fato, ou seja, uma abordagem que é dita de uma determinada maneira para determinados interlocutores que está em relação de sentido com algo que poderia ser dito e que não foi naquelas mesmas condições, também, é afetado por sentidos ligados à inovação e ao avanço na forma de apresentar a notícia.

No caso de outras materialidades - visual, som, movimentos em específico, estou tomando-as como uma unidade de significação: se a imagem/som/movimento também devem ser pensados como texto, é preciso trabalhá-los, buscando descrever seu funcionamento e expor marcas, vestígios que me encaminham para a compreensão de como as palavras e as imagens já significam, retomando sentidos inscritos na memória. A imagem no vídeo remete-nos a uma rede de filiações de memórias a outras imagens já significadas em outras condições de produção.

Orlandi (1995) discute a existência de um efeito de sobredeterminação do não verbal pelo verbal, que apagaria a especificidade do não verbal, produzindo, assim, a ilusão de uma literalidade dos sentidos. É preciso destacar que, ao contemplarmos textos jornalísticos textualizados no formato de vídeos, será necessário, assim como Orlandi defende, produzir gestos de interpretação, tendo em vista os processos específicos de significância de cada 
materialidade.

Também, em termos teóricos e analíticos, pretendo analisar o efeito da composição de vídeos digitais na versão eletrônica da revista $V e j a$, fato que me remete a um jogo entre o verbal, o visual, o musical, o cinestésico, de modo que uma materialidade vai se colocando na relação com a outra. Nesse sentido, não se trata, como afirma Lagazzi (2007, p. 3), de complementação, mas de uma relação que se dá pela contradição, pois cada materialidade, segundo a autora, faz "trabalhar a incompletude na outra".

Nesse caso, tanto o texto visual/musical/cinestésico quanto o texto verbal devem ser analisados do ponto de vista de suas especificidades, tomados como exemplar de um processo discursivo maior, constituindo uma "textualização" da memória do dizer. Assim como o texto verbal, a imagem, a música ou o efeito cinestésico também necessitam de uma discursividade anterior para significar.

Em se tratando da relação sujeito leitor e máquina, a leitura consagra-se de forma peculiar na medida em que temos um sujeito leitor permeado pelo movimento do mouse ou do toque dos dedos e pela possibilidade de uma leitura não linear. Nas palavras de Romão (2006, p.309):

[...] ao clicar no link em que a voz de outro(s) está fixada, o sujeito desvia-se do que realmente buscava na primeira entrada sua na rede. Clicando, ele desloca-se por entremeios de páginas, links e ícones que o endereçam a outros sítios, a tantas teias intertextuais nas quais se perde ou se acha. Ao ler (e interpretar, quem sabe?) a página eletrônica, o sujeito-navegador tem simultaneamente uma cartografia com várias rotas de acesso, múltiplas entradas para pisar na voz do outro, diversas janelas para abrir arquivos que, como eu disse anteriormente, já foram previamente escolhidos. No informar, cada link é uma rede em si mesma, como se por analogia cada onda do mar pudesse encerrar nela mesma um outro mar de ondas à parte. Assim, gestos de leitura e a escrita recebem nova configuração.

Vale considerar a relevância da leitura em relação às chamadas novas tecnologias de informação, considerando que a 
escola pode fomentar práticas de leitura a partir de sítios eletrônicos. Ao invés de uma leitura plana e linear, nas palavras de Coracini (2005), o que temos é um processo no qual a leitura é justamente "não hierarquizada, arborescente, em cascata, leitura de verdadeiros hipertextos".

\section{Abordagem discursiva de leitura de um vídeo digital}

Uma vez que a linguagem funciona sob o modo da textualidade, pretendo, nesta seção do artigo, apresentar uma abordagem didática da leitura de um vídeo disponibilizado no sítio eletrônico da $V e j a^{l}$, que abordou a morte do candidato à presidência Eduardo Campos e é intitulado "Multidão se despede de Campos no Recife".

Para tanto, foi realizada uma análise pré-pedagógica de tal material (textualização) para que então fossem apresentadas as bases da minha proposta de leitura de vídeos digitais, tendo como foco uma turma do primeiro ano do curso de Letras. No meu percurso de leitura, julguei o quanto é relevante destacar aos alunos e aos professores de um curso de Letras que o vídeo digital é um recurso utilizado por jornalistas e outros profissionais, sob um efeito de evidência de que é preciso informar leitores internautas e propiciar a eles um maior conhecimento sobre um determinado assunto, expandindo, assim, as fontes de informações disponibilizadas pelo ciberespaço. Também, um efeito é a produção de um texto facilitador da leitura.

Nesse aspecto, os estudos de Serrani (2005, p. 64) apontam para reflexões que colocam em cena possibilidades de compreender o texto além do material empírico, ou seja, de trabalhar a incompletude da linguagem, isto é, o que não foi dito, mas que poderia ter sido. Assim, segundo a autora, o texto não deve ser entendido como mero produto linguístico, isto é, "o texto não é apenas uma materialidade empírica com começo, meio e fim”. A autora defende a premissa na

\footnotetext{
${ }^{1}<$ http://veja.abril.com.br/multimidia/video/multidao-se-despede-de-camposno-recifel>
} 
qual "há textos anteriores e concomitantes e outros discursos com os quais o texto está relacionado, e isso faz parte das condições de leitura".

Bolognini (2009) também me oferece a possibilidade de conceber a sala de aula como lugar de movimentação de sentidos, ou seja, um sentido nem preso ao texto nem ligado à intepretação legitimada do professor ou do livro didático. Acreditamos que a leitura não pode ser trabalhada somente no sentido de competências a serem "ensinadas" ou mesmo a partir do conceito de domínio do código, o que resultaria em uma leitura tida como correta a ser controlada por todos, independentemente das condições de produção, das histórias de leitura dos sujeitos leitores. Segundo a autora, a tarefa do professor:

[...] é justamente a de oferecer aos seus alunos elementos para que discutam as condições de produção dos diversos discursos, para que as questionem, de modo que os outros sentidos, também históricos, sejam evidenciados, e eles se desloquem e ocupem outra posição-sujeito. Para a AD, o deslocamento está na possibilidade de produzir efeitos de sentido diferentes daqueles estabilizados em seu grupo social (BOLOGNINI, 2009, p. 43-44).

Em meio a tais reflexões propostas por pesquisadores filiados à AD e ligados ao domínio aplicado, um ponto que me chama a atenção diz respeito ao fato de que, diante de qualquer objeto simbólico, o sujeito é levado a dizer: o que isso significa? Tal olhar da AD dirigido para aulas de leitura pode abrir espaços para que abordagens de textualidades diversas tenham como pano de fundo discussões sobre a linguagem como um ritual com falhas (PÊCHEUX, 1990).

Neste caso, vale citar Orlandi (1988, p. 10-11), que traz três premissas que, a meu ver, representam, em termos de concepções de linguagem e de sujeito, pontos de convergência entre $\mathrm{AD}$ e estudos aplicados, a partir da (im)possibilidade de pensar: (i) um autor onipotente cujas intenções controlassem todo o processo de significação; (ii) a transparência do texto que diria por si só uma significação; e (iii) um leitor onisciente que dominasse as múltiplas determinações dos sentidos que jogam em um processo de leitura. 
Por questões de tempo e para que a abordagem não fique superficial, optei por apresentar apontamentos concernentes a um único vídeo, no sentido de problematizar as possibilidades de implementar uma abordagem discursiva de sua textualidade. Estou me inspirando em propostas de análises pré-pedagógicas empreendidas por Serrani-Infante (2000, 2005) e Baghin-Spinelli (1998), cuja finalidade foi apresentar um caminho possível de abordagem discursiva da textualidade, tendo-se vista um exame do texto que extrapole a dimensão do código. Destaco que, na abordagem discursiva, da materialidade do vídeo digital mobilizarei os conceitos de condições de produção, formação discursiva e equívoco.

\section{Condições de produção e circulação do vídeo digital}

Orlandi (2001) fala de três momentos igualmente importantes na produção do discurso: sua constituição, que se dá “a partir da memória do dizer, fazendo intervir o contexto histórico-ideológico mais amplo"; a formulação, "em condições de produção e circunstâncias de enunciação específicas"; e sua circulação, que diz respeito aos trajetos dos dizeres que se dão "em certa conjuntura e segundo certas condições" (ORLANDI, 2001, p. 9).

Diante do exposto, acredito que um conceito fundamental que precisa ser mobilizado em uma prática de leitura, neste caso voltada a um curso de Letras, diz respeito às condições de produção e circulação de tal material. Nesse sentido, o vídeo digital não é tomado em termos de comunicação de um sentido transparente, em uma dada circunstância temporal imediata. Para AD, as condições de produção envolvem a história e o imaginário discursivo que projeta as posições no discurso (a do jornalista e a imagem que esse faz de si mesmo, a imagem que o sujeito jornalista faz de seu leitor, a imagem que se tem do objeto do discurso). Assim, é necessário considerar na análise as formações imaginárias que constituem a tomada da palavra.

Em termos de condições de produção imediatas, o vídeo, base material sobre a qual são produzidos efeitos, relaciona-se a um acontecimento que comoveu a população brasileira, a morte do candidato Eduardo Campos, vítima de um acidente aéreo em plena campanha presidencial em 13 de agosto de 2014. Tendo em vista a dimensão da textualização do material que circulou no sítio eletrônico 
da Revista Veja, as condições imediatas dizem respeito às especificidades do funcionamento do jornalismo eletrônico, que representa, sob um efeito de evidência, uma leitura alternativa (com relação a textos impressos), o que se relaciona a uma projeção de possíveis leitores: leitor estudioso, leitor comum, leitor cidadão preocupado com questões políticas.

Por sua vez, as condições sócio-históricas mais amplas fazem valer sentidos inscritos no imaginário de que a morte prematura de uma figura pública produz consternação entre as pessoas e uma sensação de que uma história foi interrompida, além de que a morte desperta na população em geral diversos sentimentos de solidariedade com relação aos familiares do falecido. As condições de produção tomadas em um sentido mais amplo também têm ancoragem no préconstruído que sustenta a prática do jornalismo, de que é preciso informar e esclarecer fatos ou acontecimentos que comovem a população, como é o caso dos acidentes ou das tragédias. Em se tratando da especificidade do jornalismo eletrônico, os vídeos digitais cumprem uma função de tornar a leitura mais rápida e aprazível, além de ir ao encontro do discurso da inovação da internet, na qual o sujeito leitor encontraria "todo tipo de informação".

Outro aspecto que merece destaque diz respeito ao fato de as práticas tradicionais de leitura atravessarem os processos de leitura virtual em termos de constituição de um imaginário. Galli (2008), também produzindo um percurso transdisciplinar na Linguística Aplicada - o que envolveu aspectos ligados à leitura discursiva e à desconstrução -, afirma que as imagens que os alunos fazem de si como leitores e também do processo de leitura na tela funcionam como memória daquilo que já faz parte deles, que já os constitui. Assim, não é possível pensar numa relação de oposição entre leitura-texto-tela e leitura-texto-papel, mas é válido problematizar a dimensão "entre", ou seja, a relação de dobramento e desdobramento dos discursos, na medida em que o velho habita o novo, no caso das novas tecnologias.

$\mathrm{O}$ vídeo sob análise diz respeito a uma discursividade que, como outras, circulou em meio à internet e que também se relaciona intertextualmente com a reportagem publicada pela revista Veja, cuja capa segue abaixo, e abordou o falecimento do político Eduardo Campos em agosto de 2014.

Com efeito, o professor pode trabalhar com os acadêmicos, 
neste primeiro momento, a dimensão das condições de produção, estabelecendo conexões entre a versão da reportagem digitalizada que está presente no acervo da revista Veja com a versão impressa. No caso de outros vídeos, é relevante estabelecer conexões entre versões na tela e no papel.

1) Como se dá o gesto de leitura da versão impressa da revista? Em que meios a versão impressa circula?

2) Como é o ambiente do acervo eletrônico de Veja? Quais efeitos o gesto de organizar edições ao longo dos meses e anos produz?

Julguei válido este trabalho de contrapor a versão eletrônica, que, embora seja uma digitalização da impressa, não é a mesma versão da revista. Como a materialidade impressa sai às bancas, compreendendo fatos e acontecimentos relativos a uma semana específica e circula em bibliotecas, residências, consultórios, salas de espera, salas de aula, entre outros meios, a versão digitalizada já representa um trabalho de organizar, na forma de um arquivo, uma (nova) edição do mês corrente em meio a edições anteriores lançadas pela Editora Abril, permitindo ao sujeito internauta uma leitura na/pela tela.

Assim, achei interessante o movimento de discutir o efeitoacúmulo produzido pela tecnologia do acervo digital: as edições anteriores podem ser buscadas, pesquisadas, (re)lidas. Esse acesso a informações já publicadas pela revista durante quatro décadas nos leva a problematizar a evidência ligada ao pré-construído: "Quanto mais informações o leitor tiver, melhor será a revista/jornal”. A contradição se dá justamente no esfacelamento do efeito-novidade constitutivo da prática do jornalismo. Com efeito, a versão digitalizada de Veja não produz o furo, a novidade, mas perpetua o acontecimento, além de que torna possível ao leitor o acesso à informação, mesmo que "seja a de ontem". Graças à tecnologia do acervo eletrônico, as edições podem representar um lugar no qual os leitores encontram a informação de maneira facilitada. Em termos de relação do sujeito com a máquina, a leitura, inicialmente, se dá pelo/no gesto do clique e/ou do toque que determinam a escolha pela edição a ser lida, mas, ao acessar a revista em sua materialidade digitalizada, o sujeito leitor não tem possibilidades de acesso a novos links, somente a possibilidade de 
operar com o efeito zoom, na medida em que o texto da reportagem pode se configurar em diversos tamanhos na tela, isto é, a partir de efeitos visuais de aproximação e afastamento em relação ao objeto em foco, o leitor pode se concentrar em partes da reportagem ou imagens que mais o interessarem.

Em um segundo momento, o professor pode voltar-se para o vídeo digital propriamente dito. Neste caso, é interessante discutir com os alunos alguns pontos relacionados à interface tecnologia/leitura. Em termos de deslocamento das práticas de sala de aula, sugeri um encaminhamento no qual os sujeitos alunos trabalhem posições discursivas diversas e as coloquem em embate entre grupos de debate. Nesse caso, o professor não será o único a dar sua interpretação, mas abrirá espaço para trabalhar novas possibilidades de sentido.

1) Grupo 1 - Defender o ponto de vista de que o vídeo digital é uma formulação muito mais instigante, moderna e atualizada se comparada a uma reportagem impressa da revista Veja.

2) Grupo 2 - Defender o ponto de vista de que a versão em vídeo é muito sintética e simplificadora da "informação".

3) Grupo 3 - Defender o ponto de vista de que não importa se a leitura se produz na internet ou em material impresso, o que vale é a fonte.

\section{Práticas de leitura do vídeo: o funcionamento do texto verbal e das imagens}

Além de uma mobilização das condições de produção, outro conceito que pode ser produtivo é o de formação discursiva. Se a FD determina que, segundo Pêcheux (1988, p. 160), "aquilo que, numa formação ideológica dada, isto é, a partir de uma posição dada numa conjuntura dada, determinada pela luta de classes, determina o que pode e deve ser dito (articulado sob a forma de uma arenga, de um sermão, de um panfleto, de uma exposição, de um programa, etc.)", entendemos que, na leitura, é possível trabalhar com as posições em jogo, considerando essa relação entre o que pode e deve ser dito e o sistema da língua (na qual os processos discursivos se materializam). 
Assim, o sentido não existe em si mesmo, preso à literalidade, mas deve ser tomado com base em inscrição em FDs.

Nesse caso, em um jogo entre a transparência do dizer e a opacidade, a palavra "multidão", que integra o título, vem carregada de sentidos já naturalizados ligados ao imaginário da população que acompanha/prestigia o velório ou enterro de figuras públicas. No entanto, ao visualizar as cenas em movimento no vídeo, a palavra "multidão" desliza para "políticos que compareceram ao velório".

Nesse sentido, entendo que o professor pode encaminhar uma abordagem de cenas específicas do vídeo, mobilizando com os(as) alunos(as), de um lado, as marcas constitutivas da materialidade verbal (representada pela voz do narrador) e, de outro, as imagens postas em cena no/pelo vídeo. Um primeiro momento da abordagem envolverá as figuras 1, 2 e 3 tomadas como fotogramas recortados do vídeo digital em análise.

Título: Multidão se despede de Campos no Recife.

Subtítulo: Milhares de pessoas passaram para se despedir do candidato à Presidência pelo Partido Socialista Brasileiro (PSB), Eduardo Campos. O corpo foi enterrado no início da noite, em Recife.

Figura 1. Fotograma que marca o início do vídeo digital

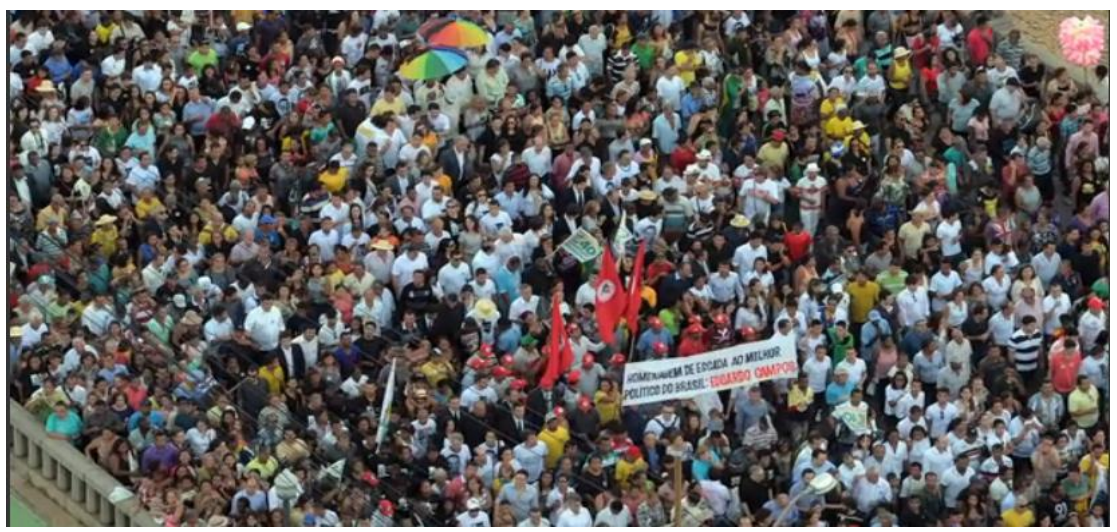

Narrador: No final da tarde, uma multidão acompanha o cortejo com o corpo de Campos. Segundo a polícia, 130 mil pessoas 
passaram em frente ao caixão durante o velório.

Figura 2. Fotograma que textualiza imagens em close-up de políticos que compareceram ao velório

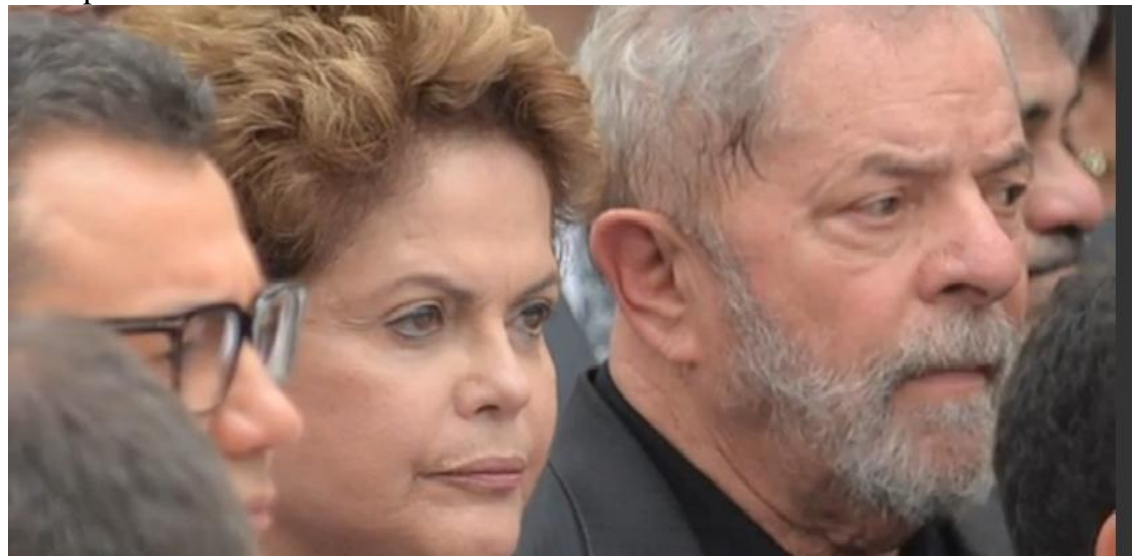

Narrador: A presidente Dilma Rousseff, candidata à reeleição, estava acompanhada do ex-presidente Luis Inácio Lula da Silva e de vários ministros. Ela foi vaiada durante missa campal celebrada em frente ao Palácio do Campo das Princesas, sede do Governo de Pernambuco.

Figura 3. Fotograma que textualiza imagens de Aécio Neves e Lula

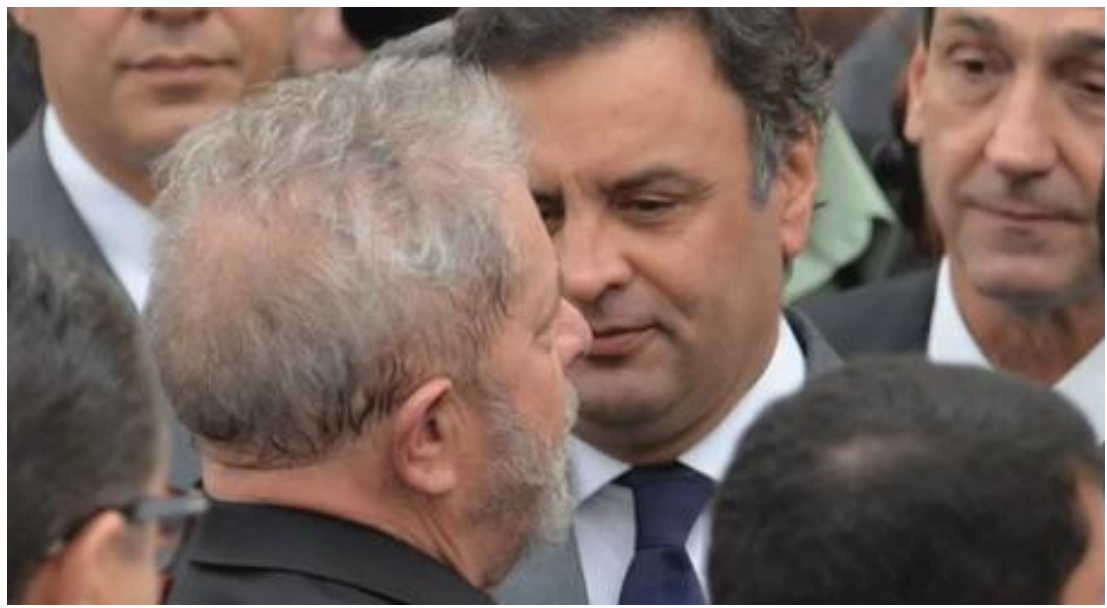

Horizontes de Linguística Aplicada, ano 16, n. 2, 2017 
Narrador: Também assistiram à cerimônia o candidato presidencial Aécio Neves, do PSDB, e a líder ambientalista e colega de chapa de Campos, Marina Silva, que, segundo a imprensa, deve ser nomeada na próxima quarta-feira para substituí-lo. Especula-se que a viúva de Campos seja vice na chapa, mas também foi mencionado o nome do deputado socialista Beto Albuquerque.

Em meio a um trabalho com o conceito de FD, saliento que, em termos de práticas de leitura, um conceito também instigante da AD diz respeito à noção de equívoco. Pêcheux (1990), com base em uma análise do enunciado "Ganhamos", proferido em meio à vitória de Mitterand, na França, em maio de 1981, "aponta a necessidade de perguntarmos pelos sentidos, em suas condições de produção, de colocarmos as interpretações em suspenso" (LAGAZZI-RODRIGUES, 2006, p. 84).

Estamos considerando que o equívoco não é visto como erro, como prega o senso comum. O equívoco é constitutivo da linguagem e diz respeito ao fato de que as palavras em funcionamento são passiveis de sentidos contraditórios, de diferentes interpretações (ORLANDI, 2001).

Nessa perspectiva, com base na materialidade linguística verbal do vídeo, o professor pode elaborar um esquema de paráfrases no qual seja possível trabalhar com aquilo que não foi dito, mas que poderia ter sido. Assim, por exemplo, pensando no gesto de nomear o vídeo (título) "Multidão se despede de Campos no Recife" e outras formulações que estão materializadas na fala do narrador, o professor pode empreender com os alunos gesto(s) de interpretação, atestando o papel do equívoco. De fato, é interessante levar às consequências a multiplicidade de possíveis formulações no mesmo sítio de significação do vídeo. Uma sugestão seria construir um esquema de paráfrases baseado em formulações verbais (materializadas pelo efeito sonoro da narração) presentes no vídeo e pensar o papel da metáfora, isto é, da possibilidade de o sentido ser outro.

Multidão se despede de Campos (título)

Milhares de pessoas passaram para se despedir do candidato à Presidência pelo Partido Socialista Brasileiro (PSB), Eduardo Campos (subtítulo) 
Segundo a polícia, 130 mil pessoas passaram em frente ao caixão durante o velório. (narração da cena 1)

A presidente Dilma Rousseff, candidata à reeleição, estava acompanhada do ex-presidente Luis Inácio Lula da Silva e de vários ministros. Ela foi vaiada durante missa campal celebrada em frente ao Palácio do Campo das Princesas, sede do Governo de Pernambuco.

Também assistiram à cerimônia o candidato presidencial Aécio Neves, do PSDB, e a líder ambientalista e colega de chapa, Marina Silva.

Se Para Pêcheux ( $A A D$ 69) efeito metafórico é um efeito semântico que se produz numa substituição contextual, o que acontece então é um deslizamento de sentido entre x e y. Quando pensamos na forma como os sentidos migram, podemos considerar o deslizamento que se dá entre "multidão", "milhares de pessoas" ou "130 mil pessoas" para "a presidente Dilma Rousseff", "candidato presidencial Aécio Neves" e "líder ambientalista e colega de chapa de Campos, Marina Silva". Em um processo de aparecimentos e silenciamentos, a partir da posição jornalística de Veja, a multidão que comparece ao vídeo é a de políticos conhecidos ou individualidades específicas postas em close up, e não a de populares anônimos. Uma vez que o título e outros enunciados que o retomam são formulações opacas, posso me perguntar pelas possibilidades de sentido: que multidão é essa que se despede de Campos? Que conjunto de pessoas compõe essa multidão? E esse tipo de problematização dos sentidos é um exercício que pode e deve ser produzido em sala com os alunos. Como diria Lagazzi (2007, p. 84), "é se expor às palavras". Uma forma de colocar em movimento sentidos silenciados.

No fotograma 2, por sua vez, a textualização do vídeo produz um silenciamento de uma imagem, a da missa citada na fala do narrador. $\mathrm{O}$ efeito que se produz é de descompasso: a imagem é um vazio e ressoa a fala "ela (Dilma) foi vaiada durante missa campal[...]". Essa falta que se produz pelo/no silêncio dessa imagem - da cena da presidente sendo vaiada - atesta uma falha no funcionamento do ritual jornalístico: o efeito verdade a ser produzido pelo material não se sustenta na relação texto/imagem, mas em uma relação de falta, de ausência da comprovação do fato.

No caso do fotograma 3, quando o candidato Aécio Neves aparece, em primeiro plano na imagem, em diálogo com Lula, mais 
uma vez o título do vídeo não mostra a multidão, mas somente figuras públicas singulares. Ademais, há a quebra de uma aparente linearidade no vídeo quando a narração passa a falar da vice-candidata na chapa de Campos, Marina Silva, a partir de duas designações: "líder ambientalista" e "colega de chapa", sem, no entanto, mostrar sua imagem. No lugar de "dar visibilidade à figura de Marina", assim como o vídeo o fizera com outros nomes políticos, há um processo de focalizar imagens do enterro no qual o caixão, coberto com a Bandeira Nacional sobre o qual se encontra uma foto do presidenciável Eduardo Campos, é abraçado por um dos seus filhos, convocando, a partir dessa imagem, sentidos já ditos e significados sobre a dor de um filho perder um pai prematuramente. A cena se fecha na foto de Campos, em uma aproximação da câmera, de modo que o discurso da imagem é marcado por um silenciamento. Na imagem de Campos, Marina Silva é uma ausência que significa.

Essa incompletude entre a fala do narrador (dimensão sonora) e as imagens (visual) se dá na medida em que a problemática da política se dá também por apagamentos que a mídia opera. $\mathrm{O}$ vídeo fala de Marina, mas não a mostra. $\mathrm{O}$ que se tem na estruturação desse vídeo digital é justamente o funcionamento da contradição: o vídeo (não) mostra o que diz ou o vídeo (não) diz o que mostra.

Acredito que, após o gesto analítico do material, o professor pode sugerir práticas de leitura que culminarão em debate e discussão sobre o tema e sobre a materialidade do vídeo digital e seus pontos de contradição na tentativa de produção de um efeito-veracidade sobre um acontecimento relevante ao país que se esfacela diante de tantos sentidos que ficam à deriva.

Assim, há de se pensar na equivocidade, na medida em que cada materialidade, a visual e a sonora (que se constitui no verbal), faz trabalhar a incompletude na outra (LAGAZZI, 2011). A partir do "mix" de cenas diversas, tais como da multidão no velório, de políticos que lá estiveram, do filho em sua dor, da campanha de Campos e da cena do acidente aéreo, o vídeo está em uma tensão entre a unidade que se pretende e a dispersão que o constitui. Mesmo tomado pelo préconstruído da necessidade de informar, o vídeo é exemplar de um material jornalístico que não garante a eficácia da produção da veracidade quanto à sua forma de divulgação. Isso se justifica pelo fato de que o vídeo digital é um processo de textualização que se dá não 
pelo movimento de imagens, o que se relaciona à cobertura de um fato no sentido de produzir a verdade, ou ainda, de mostrar a notícia em tempo real, mas por cenas congeladas do velório justapostas umas às outras. Esse efeito de colocar imagens previamente selecionadas em movimento e garantir um efeito-coerência pela junção de cenas entre si é o que determina a textualidade do vídeo: conjugando peças variadas, o que se tem, na relação com a tecnologia, é a tentativa de produção de um efeito-homogeneidade, ou seja, de uma versão dentre outras possíveis, e não a reprodução fiel do acontecimento.

Com efeito, a imbricação material do vídeo em tela se dá pela incompletude constitutiva da linguagem (Lagazzi, 2011). O vídeo produz quebras, silenciamentos e contradições, mas é justamente nesses pontos que novos sentidos podem ser reclamados.

Assim, apresento, a seguir, uma nova pergunta de leitura, considerando as possibilidades que o vídeo oferece para uma prática de autoria, na qual o sujeito aluno do curso de Letras se posiciona e reflete a respeito da historicidade do dizer. Em virtude de o vídeo ter sido disponibilizado em uma página da internet, foi proposta a prática de escrita de um comentário a ser postado em resposta ao vídeo.

Pergunta de leitura:

1) Quais os elementos que o vídeo digital "Multidão se despede de Campos no Recife" silencia e que efeitos são produzidos nos leitores internautas? Ao assistir ao vídeo, no site da revista, que comentário crítico você produziria sobre tais silêncios?

\section{Práticas de leitura e um trabalho com o efeito-fecho do vídeo}

Concordo com Gallo que entende a autoria como um esforço empreendido pelo sujeito do discurso para garantir fecho ao texto, ou seja, um efeito-autoria local. Conforme Gallo (1992, p. 58):

A assunção de autoria pelo sujeito, ou seja, a elaboração da função-autor consiste, em última análise, na assunção da "construção" de um "sentido" e de um "fecho" organizadores de todo o texto. Esse "fecho", apesar de ser 
entre tantos outros possiveis, produzirá, para o texto, um efeito de sentido único, como se não houvesse outro possivel. Ou seja, esse "fecho" torna-se "fim" por um efeito que faz parecer "único" o que é "múltiplo"; transparente o que é "ambíguo".

$\mathrm{Na}$ mesma direção, segundo Orlandi (1996, p. 76), “o fechamento do texto é, também, em si, um efeito". A partir de um gesto do autor, o fecho, entendido aqui como efeito de unidade, coerência e não contradição, emerge a partir da formulação do texto, que está relacionada tanto às condições de produção do discurso quanto ao trabalho da memória. Saliento que minhas análises deflagraram sentidos relacionados ao fotograma 4, que textualiza cenas finais do vídeo.

Considerando o efeito-fecho um processo ligado à injunção, à textualização e lugar da autoria, é interessante mobilizar com os alunos um percurso de leitura no qual sejam discutidas algumas questões de ordem discursiva:

a) Uma vez que os vídeos digitais são, geralmente, sucintos e breves, como se dá a abordagem dos fatos no vídeo "Multidão se despede de Campos no Recife?

b) Visualizando a cena 4, como foram trabalhados "dados" relacionados ao acidente que vitimou Campos?

Neste caso, o professor pode seguir um roteiro no sentido de trabalhar as determinações históricas do dizer e da produção da linguagem na contemporaneidade.

- Como o mito relacionado à informação que, graças à internet, pode ser oferecida em grande quantidade, de forma rápida e simplificada, afeta nosso modo de leitura atual?

- Com que contradições uma sociedade digital se confronta?

Com base nessas duas temáticas, o professor tem condições de abrir espaço para que diversos modos de leitura sejam problematizados na relação do sujeito com a tecnologia. Dessas reflexões emergem pontos de contradição que dão espaço a um necessário enfrentamento da complexidade da tecnologia em nossas vidas: a ilusão da liberdade 
em contraposição à necessidade de segurança na internet, a democratização de acesso em contraposição ao uso de dados pessoais de forma muito invasiva por sites, o ideal do compartilhar, de reunir (próprios das mídias sociais) em contraposição a possíveis comportamentos de isolamento e de individualismo na relação com a máquina.

Figura 4. Fotograma relacionado a um mix de cenas: a campanha e o acidente.

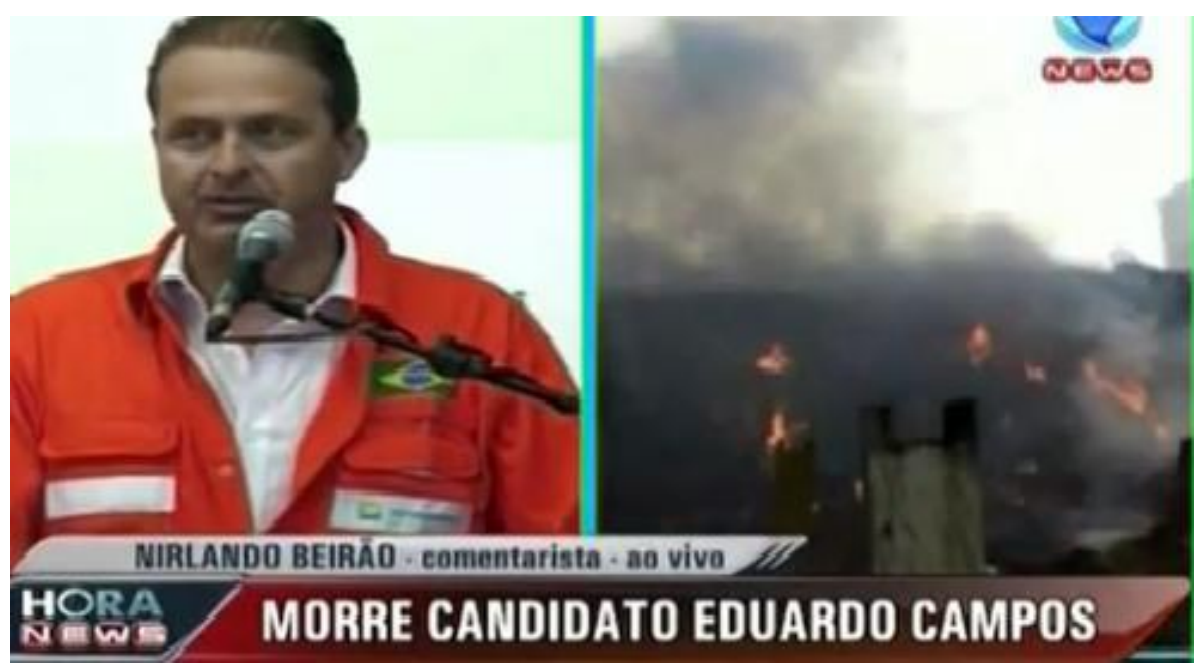

Narrador: Terceiro lugar nas pesquisas de intenção de voto para as eleições presidenciais, Eduardo Campos, de 49 anos, viajava em um jato Cesna que caiu, quarta-feira, na zona residencial de Santos, litoral de São Paulo. Morreram no acidente os 7 ocupantes da aeronove. Além do candidato, estavam a bordo assessores e dois pilotos.

Considerando a textualização do fotograma que justapõe uma cena do acidente aéreo que vitimou Campos e uma outra cena de sua campanha presidencial, o professor pode sensibilizar os alunos quanto à tecnologia digital na constituição de vídeos na internet. 
1) Na imagem do vídeo, o que se nota, na materialidade visual, é um processo de junção de uma imagem da campanha de Campos extraída do acervo da emissora Record News e a do acidente que o vitimou. Que efeitos a tecnologia de concatenar imagens produz?

As últimas cenas do vídeo apontam justamente para uma regularidade nas formulações visuais do vídeo: o de se constituir como uma "versão" do fato pela combinação (mix) de imagens previamente selecionadas e não como "reprodução fiel do acontecimento". Posso afirmar que a autoria como função de organização do discurso se produz com base em um arranjo de imagens escolhidas (no processo de seleção e edição) e agrupadas dentro de um efeito-flasback: primeiro fala-se do velório, segundo, dos políticos que lá compareceram, especula-se sobre a substituição de Campos por conta de sua morte para somente no final do vídeo o acidente aéreo emergir como fato a ser abordado. Dito de outro modo, as imagens postas em contato são advindas de outros meios e suportes e já representam um gesto de a revista Veja organizar informações sobre o fato com base em um recurso tecnológico, como são os vídeos digitais.

Em termos de encaminhamentos, é preciso considerar que a prática de leitura do vídeo é atravessada pela leitura de outros textos de maior extensão, dentre eles a reportagem exposta na capa da edição semanal da revista (disponível no acervo, mas em um texto congelado), ou mesmo de reportagens que circularam por outros meios/empresas de comunicação. Com efeito, o vídeo sobre o velório de Eduardo Campos funciona como uma síntese das informações que o sujeito leitor encontraria em textos mais longos que demandariam maior tempo de leitura. Desse modo, a produção do material aponta para sentidos ligados ao imaginário da internet como "lugar onde é possível encontrar todo tipo de informação de forma rápida e facilitada" que faz um recorte do fato que exclui outras possibilidades de arranjos ou configuração de imagens. 


\section{Considerações finais}

Tendo em vista a dimensão do ciberespaço, em minha proposta de prática de leitura voltada para uma turma de primeiro ano de um curso de Letras, busquei dirigir nosso olhar para a interdependência entre processos de formulação (especificamente dentro do jornalismo eletrônico no sentido de um arranjo de formulações visuais) e constituição de sentidos em um vídeo digital, cuja textualização se dá a partir da imbricação de diferentes linguagens (a verbal, a sonora e a cinestésica) e um trabalho de memória que joga entre o já dito e a produção de um efeito-autoria em termos de homogeneização de cenas diversas (do velório, de políticos, da propaganda de Campos no canal da Record News ou do acidente aéreo), produzindo pontos de contradição em torno do visível (cenas do velório) e do dito.

Também, tal proposta de leitura pode ser uma possibilidade de problematizar a prática jornalística, seja pelo fato de que os vídeos digitais reiteram o efeito-didatismo (também utilitário do jornalismo) próprio do funcionamento de esquemas e infográficos tomados como tecnologias utilizadas para facilitar a leitura e torná-la mais atraente dentro, obviamente, de uma inovação esperada para uma sociedade digital, pelo fato de que os vídeos participam da produção da contradição justamente no jogo da produção de um vídeo "inovador", objetivo e de acordo com a "verdade" e sua circulação permeada por silêncios, brechas e por apagamentos.

Tomando por base o conceito de discurso "como efeito de sentidos entre locutores" (PÊCHEUX, 1969, p. 82), posso ressaltar que, na proposta de leitura que busquei aqui configurar, a relação autoria e efeito-leitores que os vídeos digitais produzem, no ambiente eletrônico, supõe o batimento entre dizer o que não se mostra e/ou mostrar o que não foi dito. Assim, para alunos do primeiro ano de um curso de Letras, tal abordagem discursiva de leitura pode possibilitar justamente um (outro e talvez novo) olhar para a linguagem como algo aberto, que também falta e que escapa. A eficácia da informação ou de um sujeito pragmático que tem controle sobre o que diz se esfacela diante das falhas que o vídeo produz em seu funcionamento. 
O vídeo-digital em uma proposta de leitura...

\section{Referências}

BAGHIN-SPINELLI, Débora Cristina. Uma proposta discursiva de leitura nos cursos de formação de professores de língua inglesa. In: SERRANI, Silvana. (Org.). Fragmentos. Florianópolis: Ed. da UFSC, 2002. p. 79-100.

BOLOGNINI, Carmen Zink. O desafio para o professor a exemplo do filme 2001: Uma Odisséia no espaço. In: BOLOGNINI, Carmen Zink; PFEIFFER, Claudia; LAGAZZI, Suzy Maria. Discurso e ensino: práticas de linguagem na escola. Campinas: Mercado das Letras, 2009. p. 39-46.

CORACINI, Maria José. O jogo discursivo em sala de aula: um jogo de ilusões. Campinas: Pontes, 1995.

. Concepções de leitura na (pós) modernidade. In: LIMA, Regina Célia Paschoal (Org.). Leitura: múltiplos olhares. Campinas: Mercado das Letras; São João da Boa Vista: Unifeob, 2005. p. 15-44.

DIAS, Cristiane; COUTO, Olívia Ferreira do. As redes sociais na divulgação e na formação do sujeito do conhecimento: compartilhamento e produção através da circulação de ideias. Linguagem em (Dis)curso, Tubarão, SC, v. 11, n. 3, p. 631-648, set./dez. 2011.

GALLI, Fernanda Silveira. Ciber)espaço e leitura: o mesmo e o diferente no discurso sobre as "novas" práticas contemporâneas. 2008. Tese (Doutorado em Linguística Aplicada) - Instituto de Estudos da Linguagem. Unicamp. Campinas, 2008.

GALLO, Solange. Discurso da escrita e ensino. Campinas: Ed. da Unicamp, 1992.

LAGAZZI-RODRIGUES, Suzy Maria. Texto e autoria. In: ORLANDI, Eni; LAGAZZI-RODRIGUES, Suzy Maria (Org.).

Discurso e textualidade. 1. ed. Campinas: Pontes, 2006. p. 81-104. . O recorte significante na memória. In: INDURSKY, F. et al. (Org.). O discurso na contemporaneidade: materialidades e fronteiras. 
São Carlos: Claraluz, 2009.

. A equivocidade na circulação do conhecimento científico.

Linguagem em (dis)curso, Tubarão, v. 11, n. 3, p. 497-514, dez. 2011.

. O recorte e o entremeio: condições para a materialidade significante. In: RODRIGUES, Eduardo A. et al. Análise do discurso no Brasil: pensando o impensado sempre: uma homenagem a Eni Orlandi. Campinas: Editora RG, 2011.

NECKEL, Nádia. Tessitura e tecedura: movimentos de compreensão do discurso artístico no audiovisual. 2010. Tese (Doutorado em Linguística) - Instituto de Estudos da Linguagem, Unicamp.

Campinas, 2010.

NUNES, Sílvia Regina. A geometrização do dizer no discurso infográfico. 2012. Tese (Doutorado em Linguística) - Instituto de Estuados da Linguagem. Unicamp. Campinas, 2012.

ORLANDI, Eni. Discurso e leitura. São Paulo: Cortez, 1988.

. Efeitos do verbal sobre o não verbal. Revista Rua, Campinas, n. 1, p. $35-47,1995$.

Interpretação: autoria, leitura e efeitos do trabalho simbólico. Campinas: Pontes, 1996.

Pontes, 1999.

Análise de discurso: princípios e procedimentos. Campinas:

. Discurso e texto. Campinas: Pontes, 2001.

. Análise de discurso. In: ORLANDI, E. P.; LAGAZZI-

RODRIGUES, R. R. (Org.). Discurso e textualidade. 1 ed. Campinas: Pontes, 2006. v. 1, p. 81-104

A contrapelo: incursão teórica na tecnologia: discurso

eletrônico, escola, cidade. RUA [online]. 2010, n. 16. v. 2 - ISSN 
O vídeo-digital em uma proposta de leitura...

1413-2109. Consultada no Portal Labeurb - Revista do Laboratório de Estudos Urbanos do Núcleo de Desenvolvimento da Criatividade Disponível em: <http://www.labeurb.unicamp.br/rua/>.

PÊCHEUX, Michel. Semântica e discurso: uma crítica à afirmação do óbvio. Trad. Eni P. de Orlandi et al. Campinas: Editora da Unicamp, 1988. (1 $1^{\mathrm{a}}$. ed. 1975).

Análise automática do discurso (AAD 69). In: GADET, F.; HAK, T. (Org.). Por uma análise automática do discurso: uma introdução à obra de Michel Pêcheux. Trad. Bethânia S. Mariani et al. Campinas: Ed. da Unicamp, 1990. p. 61-162.

ROMAO, Lucília Maria Souza. O cavalete, a tela e o branco: introdução à autoria na rede eletrônica. DELTA [online], v. 22, n. 2, p. 303-328, 2006.

SERRANI, Serrani. Discurso sobre a língua, textualidade e línguas estrangeiras próximas. In: Anais da ANPOLL, Niterói, RJ, 2000.

. Discurso e cultura na aula de línguas: Currículo - Leitura Escrita. Campinas: Pontes, 2005.

Recebido em: 08/05/2017

Aceito em: 08/09/2017

Title: The digital video in a reading proposal in mother tongue under a discursive approach 